REVISTA DE DERECHO UNED, NÚM. 10, 2012

\title{
CONFORMIDAD Y PLURALIDAD DE ACUSADOS
}

\author{
Marta LOZANo EIROA \\ Profesora del Departamento de Derecho Procesal \\ Universidad Nacional de Educación a Distancia (UNED)
}

Resumen: La conformidad en supuestos de pluralidad de acusados aparece regulada en los artículos 655 y 697 de la LECrim, que establecen que sólo será procedente cuando sea prestada por todos los acusado y el Letrado de ninguno de ellos estime necesaria la continuación del Juicio. Este trabajo tiene por objeto analizar diversos supuestos procesales en los que puede concurrir una pluralidad de acusados, con el propósito de determinar en qué supuestos y bajo qué condiciones ha de entenderse superada la genérica prohibición y, en consecuencia, cabe la conformidad parcial.

Abstract: Plea bargain in cases of plurality of defandants is regulated in articles 655 and 697 of the Criminal Procedure Law, which states that it will only be appropriate when provided by all the defendants and the attorney of neither of them deem necessary the Trial. This work aims to analyze various procedural assumptions on which a plurality of defendants can attend, with the purpose of determining in what circumstances and under what conditions, partial plea bargain can be allowed.

Palabras Clave: conformidad, pluralidad de acusados, sentencias contradictorias.

Key Words: plea bargain, plurality of defendants, contradictory judgments.

Sumario: I. Introducción. II. Pluralidad de partícipes en una misma causa. III. Pluralidad de acusados y delitos conexos. IV. Conformidad en ausencia de algún acusado V. Especial referencia a la pluralidad de acusados en la "conformidad premiada». VI. Conclusiones.

(C) UNED. Revista de Derecho UNED, núm. 10, 2012 


\section{INTRODUCCIÓN}

La parte pasiva contra la que se dirige la pretensión en los procesos penales puede estar compuesta por un sólo acusado o por varios. No suscita problema alguno dotar de plenos efectos a la conformidad que, voluntariamente y, con el consentimiento de sus Abogados, deciden prestar los coacusados de una misma causa. El problema, sin embargo, se origina cuando alguno o algunos de los acusados declaran no estar conformes o sencillamente, ante la pregunta que se les dirige en relación a su responsabilidad, deciden guardar silencio.

Las sucesivas reformas operadas en la LECrim relativas al instituto de la conformidad no han incorporado precepto alguno que contribuya a ofrecer una solución a la referida cuestión. Por este motivo, ante supuestos de conformidad en los casos de pluralidad de acusados, la práctica forense proyecta como base procedimental para dar respuesta a la cuestión planteada los preceptos previstos para la conformidad del sumario ordinario, independientemente del proceso a través del cual se sustancie la causa, sin perjuicio de las aclaraciones que, posteriormente se realizarán en relación a la regulación de los supuestos de pluralidad de acusados en la conformidad premiada de los juicios rápidos.

En una primera aproximación al tema objeto de estudio, podemos adelantar que la cuestión planteada no ofrece una respuesta unívoca, motivo por el cual, deviene necesario efectuar un análisis separado de las diversas situaciones procesales en las que pueden concurrir una pluralidad de acusados, esto es, los casos en los que la pluralidad de acusados responde a un supuesto de participación en un mismo hecho delictivo, aquellos otros en los que confluyen los denominados delitos conexos, los supuesto de conformidad en ausencia de algún acusado y, por último, las particularidades que encierra la pluralidad de acusados en la conformidad premiada.

\section{PLURALIDAD DE PARTÍCIPES EN UNA MISMA CAUSA}

La LECrim, en sus artículos 655.4, 697.2, 698, referidos al procedimiento ordinario, y de aplicación supletoria en el resto de procesos, ofrece una respuesta categórica a la referida hipótesis al señalar que, en caso de pluralidad de acusados, sólo será procedente la conformidad cuando sea prestada por todos los acusados, y el Letrado de ninguno de ellos repute necesaria la continuación del Juicio. En cualquier otro caso, la Ley ordena la prosecución del juicio, por los cauces normales, 
para todos los acusados sin que la conformidad despliegue ninguno de sus efectos ni tan siquiera para aquellos que sí se conformaron.

La doctrina procesal ${ }^{1}$ justifica, desde antaño, la inteligencia de los referidos preceptos sobre la base de dos cuestiones fundamentales: de un lado, se manifiesta la preferencia el juicio completo frente al truncado, habida cuenta que la contradicción y la práctica de la prueba refuerzan la probabilidad de acierto de la sentencia y, de otro, se argumenta la necesidad de preservar la continencia de la causa, evitando la posibilidad de sentencias contradictorias ${ }^{2}$, pues, tal y como apuntaba el Tribunal Supremo en su Sentencia de 27 de julio de 1998, "que un hecho se considere al mismo tiempo cierto por conformidad, e incierto por el resultado de las pruebas, es un contrasentido evitado con la exigencia de la unanimidad de los acusados al conformarse con la calificación, y la necesidad de celebrarse el juicio oral para todos cuando la conformidad sólo es dada por algunos» ${ }^{3}$.

Así, pues, tanto la doctrina como la jurisprudencia sostienen, ante la existencia de una pluralidad de imputados en una misma causa (por haber sido acusados de participar en un mismo hecho punible, en concepto de coautores, cómplices o cooperadores ${ }^{4}$ ), la necesidad de enjuiciar a todos los coacusados en el mismo proceso y a través de una misma sentencia. Ahora bien, de lo dicho no debe extraerse la

1 Cfr. AGUILERA DE PAZ, Enrique, Comentarios a la Ley de Enjuiciamiento Criminal, Ed. Reus, Madrid, 1914, Tomo V, págs. 88-89; ALCALÁ ZAMORA y CASTILLO, N., El allanamiento en el proceso penal, Ed. Jurídicas Europa-América, Buenos Aires, 1962, págs. 61 y, 85 y ss.; GIMENO SENDRA, V., Derecho procesal penal, Ed. Colex, $2^{a}$ edición, Madrid, 2007, pág. 635; GÓMEZ COLOMER, J. L., con MONTERO AROCA, J., MONTÓN REDONDO, A. y, BARONA VILAR, S., Derecho Jurisdiccional III, Ed. Tirant lo Blanch, $14^{\text {a }}$ edición, Valencia 2005, pág. 273; MIRA ROS, M. C. Régimen actual de la conformidad, MIRA ROS, M. C., Régimen actual de la conformidad, Ed. Constitución y Leyes, S.A., Madrid, 1998, pág. 370 y, DE DIEGO DÍEZ, L. A., La conformidad del acusado, Ed. Tirant Lo Blanch, Valencia, 1997, pág. 339.

2 Por el contrario, Aguilera Morales entiende que "cuando el legislador prevé la continuación del proceso para el caso de que no todos se conformen, no lo hace para evitar la división de la continencia de la causa, sino para garantizar el derecho a un proceso público con todas las garantías respecto de los disconformes y el derecho de defensa respecto de los conformes». Cfr. AGUILERA MORALES, M., El principio de consenso. La conformidad en el proceso penal español. Ed. Cedecs, Barcelona, 1998, pág. 85.

${ }_{3}$ Cfr. Sentencia del Tribunal Supremo no 971/1998, de 27 de julio de 1998.

${ }^{4} \mathrm{El}$ art. $28 \mathrm{CP}$ establece que «Son autores quienes realizan el hecho por sí solos, conjuntamente o por medio de otro del que se sirven como instrumento. También serán considerados autores: a) Los que inducen directamente a otro u otros a ejecutarlo. b) Los que cooperan a su ejecución con un acto sin el cual no se habría efectuado". Por su parte, el art. $29 \mathrm{CP}$ dispone que serán cómplices «los que, no hallándose comprendidos en el artículo anterior, cooperan a la ejecución del hecho con actos anteriores o simultáneos.». 
existencia de una comunidad de suerte para todos los acusados, pues, como es sabido, el ius puniendi, con carácter general, se proyecta sobre conductas humanas diferentes, con independencia de que todas ellas incidan en un mismo hecho. En definitiva, el órgano de enjuiciamiento será libre de apreciar la culpabilidad de unos y la inocencia de otros, motivo por el cual, en el fallo de la sentencia se reflejará un tratamiento individualizado de cada uno de los acusados ${ }^{5}$.

Existen, sin embargo, algunos ejemplos aislados en la jurisprudencia menor (entre otras, de las Audiencias Provinciales de Barcelona, Badajoz y Murcia ${ }^{6}$ ) que se alejan de la prescripción legal y admiten, en el procedimiento abreviado, la conformidad parcial subjetiva, continuando la celebración del juicio únicamente con respecto a los acusados disconformes para, posteriormente, reflejar en la sentencia, de un lado, respecto al conforme, la pena conformada y, de otro, a la luz de la prueba practicada en el juicio, la condena o absolución del resto de los acusados. Así, a modo de ejemplo, la Audiencia Provincial de Barcelona en su sentencia de 31 de julio de 2009 dispone que, en el acto de la vista oral, el acusado y su defensa, manifestaron su expresa conformidad con la calificación jurídica y con la pena solicitada, conforme a lo establecido en el art. 787 LECrim, motivo por el cual, «se prosiguió el juicio únicamente con respecto al otro coacusado» ${ }^{7}$.

Dicha solución pudiera resultar, en principio, encomiable, toda vez que parece compaginar la conformidad como manifestación del derecho de defensa y la necesidad de dictar una única sentencia para los acusados conformes y disconformes. Ello no obstante, no parece que sea una solución acertada toda vez que, si practicadas las pruebas se demuestra la inocencia de los disconformes, el Tribunal los absolverá, pero mantendrá la condena aceptada para el conforme que, por el hecho de allanarse a la pretensión, renunció a la prueba y, por ende, a la posibilidad de adherirse a su resultado.

Como advierte DE DIEGO ${ }^{8}$, la posibilidad de que, sujetos respon-

5 Cfr. GIMÉNEZ SÁNCHEZ, I., Pluralidad de partes en el proceso penal. Ed. McGraw-Hill, Madrid, 1998, págs. 184 y 185; DE DIEGO DÍEZ, L. A., La conformidad del acusado, op. cit., pág. 347; AGUILERA MORALES, M., El principio de consenso. La conformidad en el proceso penal español, op. cit., pág. 85.

${ }^{6}$ Cfr. Sentencia de la Audiencia Provincial de Barcelona 253/2009, de 31 de julio (Secc. 9a); Sentencia de la Audiencia Provincial de Badajoz 106/2009, de 22 de mayo (Secc. $3^{\mathrm{a}}$ ) y, Sentencia de la Audiencia Provincial de Murcia 21/2010, de 3 de febrero $\left(\right.$ Secc. $\left.3^{\mathrm{a}}\right)$.

${ }^{7}$ Cfr. Sentencia de la Audiencia Provincial de Barcelona 253/2009, de 31 de julio (Secc. $9^{\mathrm{a}}$ ).

${ }^{8}$ Cfr. DE DIEGO DÍEZ, L. A., La conformidad del acusado, op. cit., pág. 344. 
sables de unos mismos hechos y en idénticas circunstancias sean objeto de sanciones distintas, llegando incluso a la condena de los que se conformaron y a la absolución de los que disintieron, provocaría una situación notoriamente injusta con grave desprestigio de la función jurisdiccional. Por tal razón, el Tribunal Supremo, como máximo garante de la legalidad ordinaria, en su reciente sentencia de 11 de febrero de 2011, recuerda que cabrá recurso contra la parte dispositiva de la sentencia penal que acuerda la conformidad cuando ésta no haya sido prestada por la totalidad de los acusados ${ }^{9}$.

Por consiguiente, y sin perjuicio de se pueden encontrar en la práctica judicial ejemplos aislados que lo posibilitan, admitir la conformidad parcial subjetiva en supuestos como el analizado, contradice el tenor de la Ley, rompe la continencia de la causa y sería una solución susceptible de generar una autentica indefensión al acusado disconforme que soportaría la celebración de un juicio presidido por un órgano de enjuiciamiento, inevitablemente, influido por las declaraciones de los acusados conformes que, además, a tenor de lo establecido, tanto por la Circular de la Fiscalía General del Estado 1/2000, como por el Acuerdo del Pleno no jurisdiccional de la Sala $2^{\mathrm{a}}$ del Tribunal Supremo, de 16 de diciembre de $2008^{10}$, serían llamados a declarar, a partir de entonces, como testigos.

Sentado lo anterior, esto es, la prohibición de la conformidad parcial subjetiva en los supuestos de pluralidad de partícipes en una misma causa, conviene precisar que, la práctica forense demuestra que no son extraños los supuestos en los que el acusado que interesó la conformidad, posteriormente frustrada por la decisión de los demás acusados, ratifica, en el juicio, su participación en los hechos, así como la del resto de partícipes, por cuanto que dicha colaboración es susceptible de generar una modificación parcial de las conclusiones acusatorias definitivas por aplicación de la atenuante analógica de confesión prevista en el art. 21.7 ${ }^{\mathrm{a} 11}$, en relación con el

${ }^{9}$ Cfr. Sentencia del Tribunal Supremo n ${ }^{\circ}$ 88/2011 de 11 de febrero de 2011.

${ }^{10}$ El Acuerdo del Pleno no jurisdiccional de la Sala $2^{\mathrm{a}}$ del Tribunal Supremo, de 16 de diciembre de 2008, no dudó en establecer que "La persona que ha sido juzgada por unos hechos y con posterioridad acude al juicio de otro imputado para declarar sobre esos mismo hechos, declara en el plenario como testigo y, por tanto, su testimonio debe ser valorado en términos racionales para determinar su credibilidad».

11 Dispone el art. 21.7 ${ }^{\mathrm{a}}$ (anterior $21.6^{\mathrm{a}}$ antes de la reforma operada por LO 5/2010, de 22 de junio) que será circunstancia atenuante, "cualquier otra circunstancia de análoga significación que las anteriores».

$12 \mathrm{El}$ art. 21.4 CP señala que será circunstancia atenuante «La de haber procedido el culpable, antes de conocer que el procedimiento judicial se dirige contra él, a confesar la infracción a las autoridades». 
art. 21.4 ${ }^{\text {a12 }}$. Por tal razón, parece que, si bien es cierto que la Administración de Justicia secunda la prohibición de la conformidad parcial subjetiva, no lo es menos que consiente sucedáneos de la misma en tanto contempla ventajas para quien reitera su anterior declaración ${ }^{13}$.

\section{PLURALIDAD DE ACUSADOS Y DELITOS CONEXOS}

Por lo que se refiere a aquellos supuestos en los que se enjuician en un único proceso una pluralidad de delitos, si bien la Ley prohíbe la conformidad parcial objetiva toda vez que, exige que el acusado se conforme respecto de todos los delitos imputados, deja huérfana de regulación legal la eventualidad de que, los delitos conexos hayan sido cometidos por una pluralidad de acusados, y no todos ellos manifiesten su conformidad.

Así, de conformidad con lo establecido en el art. 697 LECrim, que se refiere expresamente a la hipótesis de la conformidad en los casos de pluralidad de acusados, todos los acusados habrán de aceptar la comisión "del delito o delitos» que les hayan sido atribuidos en los escritos de calificación, a los efectos de obtener una sentencia de conformidad en los términos expresados en el art. 655 LECrim $^{14}$.

El citado precepto secunda, pues, la excepción prevista en el art. 300 LECrim que, tras fijar la norma de que cada delito del que conozca la Autoridad Judicial será objeto de un sumario, establece la correspondiente excepción al decir que «los delitos conexos se comprenderán, sin embargo, en un solo proceso» ${ }^{15}$. Del referido precepto se

13 Cfr. MOLINA GIMENO, F. J., «La imposibilidad de conformidad parcial ante la concurrencia de acusados y pluralidad de delitos objeto de acusación» en, Diario La Ley, Año XXXI, nº 7336, viernes 5 de febrero de 2010, pág. 8.

${ }_{14}$ La doctrina clásica no dudó en secundar los requisitos exigidos por los preceptos transcritos y, a tal efecto, reclamaba la necesidad de que la conformidad fuera prestada por todos los acusados y con respecto a todos los delitos acumulados en el proceso. Cfr. AGUILERA DE PAZ, E., Comentarios a la Ley de Enjuiciamiento Criminal, Tomo V, op. cit., págs. 88-89 y 372 y, ALCALÁ ZAMORA Y CASTILLO, N., El allanamiento en el proceso penal, op. cit., págs. 85 y 86.

${ }_{15}$ Los supuestos de conexión aparecen recogidos en el art. 17 LECrim, en virtud del cual: "Considérense delitos conexos:

1. ${ }^{\circ}$ Los cometidos simultáneamente por dos o más personas reunidas, siempre que éstas vengan sujetas a diversos Jueces o Tribunales ordinarios o especiales, o que puedan estarlo por la índole del delito.

2. ${ }^{\circ} \quad$ Los cometidos por dos o más personas en distintos lugares o tiempos si hubiera precedido concierto para ello. 
infiere, tal y como apunta GÓMEZ COLOMER ${ }^{16}$, que todos los sujetos pasivos deben ser sometidos a una sola causa y enjuiciados en una misma sentencia, con independencia de que ésta pueda tener diversos contenidos según los acusados.

Ello no obstante, cuando en un proceso se enjuician distintos hechos delictivos acumulados por razones de conexidad, que se imputan de manera independiente a distintos acusados, tanto la doctrina ${ }^{17}$ como la práctica forense ${ }^{18}$ se han decantado por superar la genérica prohibición de la conformidad parcial (contemplada en los arts. 655.4 y 697 LECrim).

Tal posibilidad encuentra un sólido apoyo legal en el art. $762.6^{\mathrm{a}}$ LECrim ${ }^{19}$ que, por razones de simplificación o rapidez en el proceso, otorga al Juez, en el marco del proceso penal abreviado, la facultad de acordar la formación de las piezas separadas que resulten convenientes, cuando existan elementos que permitan el enjuiciamiento in-

3. Los cometidos como medio para perpetrar otros o facilitar su ejecución.

4. ${ }^{\circ}$ Los cometidos para procurar la impunidad de otros delitos.

5. ${ }^{\circ}$ Los diversos delitos que se imputen a una persona al incoarse contra la misma causa por cualquiera de ellos, si tuvieren analogía o relación entre sí, a juicio del Tribunal, y no hubiesen sido hasta entonces Sentenciados».

${ }^{16}$ Cfr. GÓMEZ COLOMER, J. L., con MONTERO AROCA, J., MONTÓN REDONDO, A. y, BARONA VILAR, S., Derecho Jurisdiccional III, 14ª edición, op. cit., pág. 110.

17 En este sentido se expresan, entre otros, GÓMEZ COLOMER, J. L., con MONTERO AROCA, J., MONTON REDONDO, A. y, BARONA VILAR, S., Derecho Jurisdiccional III, $14^{\mathrm{a}}$ edición, op. cit., pág. 273 quien señala que «la disconformidad de uno de los acusados, siendo varios, obliga a la continuar el juicio para todos ellos, incluidos aquellos que se conformaron (art. 655 IV LECrim), salvo, que pueda dividirse el objeto siendo varios los acusados por diversos delitos»; DE DIEGO DÍEZ, L. A., La conformidad del acusado, op. cit., pág. 343; AGUILERA MORALES, M., El principio de consenso. La conformidad en el proceso penal español. op. cit., pág. 87; DÍAZ PITA, M. P., Conformidad, reconocimiento de hechos y pluralidad de imputados en el procedimiento abreviado, Ed. Tirant lo Blanch, Valencia, 2006, págs. 47 y ss y, MOLINA GIMENO, F. J., "La imposibilidad de conformidad parcial ante la concurrencia de acusados y pluralidad de delitos objeto de acusación» en, Diario La Ley, op. cit., pág. 8.

${ }_{18}$ Cfr., entre otras, Sentencia del Tribunal Supremo n ${ }^{\circ}$ 985/2011, de 28 de septiembre de 2011; Sentencia de la Audiencia Provincial de Lleida (Secc. $1^{\text {a }}$ ) $n^{\circ}$ 142/2004, de 23 de marzo de 2004; Sentencia de la Audiencia Provincial de Guadalajara (Secc. $\left.1^{a}\right) n^{\circ}$ 18/2007, de 13 de abril de 2007 y, Sentencia de la Audiencia Provincial de Badajoz (Secc. $1^{\text {a }}$ ) $n^{\circ}$ 38/2009, de 5 de marzo de 2009.

19 El Art. 762.6 ${ }^{\mathrm{a}}$ dispone textualmente: "Para enjuiciar los delitos conexos comprendidos en este Titulo, cuando existan elementos para hacerlo con independencia, y para juzgar a cada uno de los imputados, cuando sean varios, podrá acordar el Juez la formación de las piezas separadas que resulten convenientes para simplificar y activar el procedimiento». 
dependiente de cada uno de los imputados ${ }^{20}$. Por tal razón, deberá comprobarse, con carácter previo, la naturaleza de los delitos conexos toda vez que, tratándose de hechos homogéneos no debiera permitirse el enjuiciamiento por separado pues, dicha solución sería susceptible de generar sentencias contradictorias o, dicho en otras palabras, tan sólo debiera acordar el Juez la formación de piezas separadas en aquellos casos en los que los delitos acumulados sean de carácter heterogéneo.

De lo dicho se colige que no existe inconveniente alguno en admitir la conformidad parcial subjetiva en las causas por delitos conexos, toda vez que, a tenor de lo dispuesto en el art. 762. $6^{\mathrm{a}}$ LECrim, el Juez abriría una pieza separada en aras a dictar sentencia de conformidad para el acusado o acusados conformes, sin perjuicio de la continuación del proceso por los cauces normales para los demás, que estarían acusados por hechos distintos a los que fueron objeto de la sentencia de conformidad ${ }^{21}$.

Es evidente, pues, que tanto el citado precepto como la práctica forense ${ }^{22}$, abonan la tesis secundada, desde antaño, por un sector doctrinal $^{23}$, según la cual, la regla de enjuiciamiento conjunto de los delitos conexos prevista en el art. 300 LECrim, no es una regla imperativa, sino, antes al contrario, habrá de ceder ante razones de eficacia y de aceleración del procedimiento, en tanto en cuanto sea posible diferenciar los concretos hechos que se le imputan a cada uno de los

${ }^{20}$ En este sentido se pronunciaba la Fiscalía General del Estado, en su Consulta $1 / 2000$, de 14 de abril al señalar que cuando se trate de distintos hechos imputados a distintos acusados, la regla del art. 784.7 (actual art. $762.6^{\circ}$ LECrim), parece orientarse a favor de admitir la posible conformidad por separado.

${ }^{21}$ En este sentido se expresan, entre otros, GÓMEZ COLOMER, J. L., con MONTERO AROCA, J., MONTON REDONDO, A. y, BARONA VILAR, S., Derecho Jurisdiccional III, $14^{\text {a }}$ edición, op. cit., pág. 273 quien señala que «la disconformidad de uno de los acusados, siendo varios, obliga a la continuar el juicio para todos ellos, incluidos aquellos que se conformaron (art. 655 IV LECrim), salvo, que pueda dividirse el objeto siendo varios los acusados por diversos delitos»; DE DIEGO DÍEZ, L. A., La conformidad del acusado, op. cit., pág. 343 y, MOLINA GIMENO, F. J., "La imposibilidad de conformidad parcial ante la concurrencia de acusados y pluralidad de delitos objeto de acusación» en, Diario La Ley, op. cit., pág. 8.

${ }_{22}$ Cfr., entre otras, Sentencia del Tribunal Supremo n ${ }^{\circ}$ 985/2011, de 28 de septiembre de 2011; Sentencia de la Audiencia Provincial de Lleida (Secc. $1^{a}$ ) no 142/2004, de 23 de marzo de 2004; Sentencia de la Audiencia Provincial de Guadalajara (Secc. $\left.1^{\mathrm{a}}\right) \mathrm{n}^{\circ}$ 18/2007, de 13 de abril de 2007 y, Sentencia de la Audiencia Provincial de Badajoz (Secc. $1^{\text {a }}$ ) $n^{\circ}$ 38/2009, de 5 de marzo de 2009.

${ }^{23}$ Cfr. DE LA OLIVA SANTOS, A., La conexión en el proceso penal, Ed. Universidad de Navarra, S.A., Pamplona, 1972, pág. 83; DE DIEGO DÍEZ, L. A., La conformidad del acusado, op. cit., pág. 346. 
acusados $^{24}$. Por ello, tal y como apunta DE LA OLIVA ${ }^{25}$, las razones aducidas en pro de justificar la reunión en un solo proceso de los delitos conexos, esto es, impedir la ruptura de la continencia de la causa con el fin de evitar la posibilidad de sentencias contradictorias y dar cumplimiento al principio de economía procesal ${ }^{26}$, deberán ser ponderadas en cada caso concreto, pues, según los casos, la acumulación podría no ser la solución más conveniente.

Un ejemplo ilustrativo de dicha posibilidad se encuentra en la reciente solución adoptada, con ocasión del juicio por cohecho pasivo impropio del ex presidente de la Generalitat Valenciana Francisco Camps, por el Magistrado Presidente del Tribunal Superior de Justicia de Valencia, D. Juan Climent Barberá quien, finalmente decidió dictar dos Sentencias anticipadas de conformidad para los dos acusados que manifestaron su intención de conformarse, por entender que «en el presente caso se ha de estimar que los hechos constitutivos de delito que se imputan a los acusados en este proceso, aun cuando sean de las mismas características fácticas -fundamentalmente la aceptación del regalo de prendas vestir en consideración al cargo público que desempeñaban-, sean dadivas entregadas desde el mismo grupo de personas y tenuidades y se integren en una misma calificación jurídico penal de las acusaciones formuladas -el delito continuado de cohecho impropio-, es lo cierto que vienen referidos a contenidos distintos -aceptación de diferentes prendas y objetos, en número y tipo-, producidos en fechas diferentes, y en su caso realizados por autores diferentes, y por tanto a hechos, autores y delitos distintos, cuyo enjuiciamiento en definitiva aunque se celebre conjuntamente ha de venir referido a cada uno de ellos, pudiendo dar lugar a resultados distintos respecto de cada uno de los acusados, como se desprende de los mismos escritos de acusación que atribuyen hechos, formulan calificaciones y piden pe-

${ }^{24}$ Dicha posibilidad ha sido contemplada expresamente en el Anteproyecto de la Ley de Enjuiciamiento Criminal al disponer expresamente en su art. 22 las «Excepciones en caso de conexidad» en virtud del cual, se seguirán procedimientos distintos: «a) si la unidad del procedimiento retrasa excesivamente el enjuiciamiento de los investigados o acusados. b) Si ha de acordarse la suspensión del procedimiento por causa referida a uno de los hechos o a uno de los acusados. c) Si culmina la investigación respecto de uno de los hechos justiciables y es necesario continuarla respecto de otros».

${ }_{25}$ Cfr. DE LA OLIVA SANTOS, A., La conexión en el proceso penal, op. cit., págs. 77 y ss.

${ }^{26}$ Cfr. en este sentido, GÓMEZ COLOMER, J. L., con MONTERO AROCA, J., MONTÓN REDONDO, A. y, BARONA VILAR, S., Derecho Jurisdiccional III, $14^{\mathrm{a}}$ edición, op. cit., pág. 109 y DE LA OLIVA SANTOS, A. con ARAGONESES MARTÍNEZ, S., HINOJOSA SEGOVIA, R., MUERZA ESPARZA, J. y, TOMÉ GARCÍA, J. A., Derecho procesal penal, Ed. Universitaria Ramón Areces, $7^{\mathrm{a}}$ edición, Madrid 2004, pág. 229. 
nalidades de forma específica y singular para cada uno de los acusados» ${ }^{27}$.

En contra de dicho pronunciamiento, sin embargo, pudiera argumentarse que el enjuiciamiento separado de los distintos acusados sería susceptible de generar pronunciamientos contradictorios. Cierto es, tal y como advierte DE LA OLIVA ${ }^{28}$, que tratándose de delitos conexos, no parece que, en rigor, pueda hablarse de sentencias contradictorias, pues, como puntualiza el referido autor, lo más grave que podría suceder, en caso de sustanciarse un proceso distinto por cada delito, sería que se apreciara de distinta manera por cada órgano jurisdiccional el elemento de parcial coincidencia en el que estuviera fundada la conexión, sin que el referido elemento tenga relevancia en la decisión propiamente dicha. Por ello, y en atención al tema que nos ocupa, la condena del acusado conforme, en los supuestos de delitos conexos, no incidiría en los límites objetivos y subjetivos de la cosa juzgada de los disconformes, habida cuenta que, la decisión del órgano de enjuiciamiento no recaerá sobre el mismo objeto procesal, pues, cada acusado está siendo juzgado por un delito distinto ${ }^{29}$.

Ello no obstante, en mi opinión, asumir dicho argumento en el conocido periodísticamente como "Caso Camps» genera serias dudas, toda vez que, aunque formalmente sean cuatro delitos de cohecho impropio pasivo, el hecho es el mismo. Por tal razón, entiendo que en esta ocasión el Tribunal Superior de Justicia de Valencia no debiera haber dictado sentencia de conformidad, pues, tratándose de un mismo hecho, no existen elementos para juzgarles con independencia.

Adviértase, además, que en el juicio posterior celebrado contra los acusados disconformes, el jurado popular emitió veredicto de inculpabilidad por entender que no estaba suficientemente probado el delito de cohecho impropio por el que estaban acusados ${ }^{30}$, rompiendo la continencia de la causa, toda vez que ha dado lugar a una situación en la que un mismo hecho ha sido considerado cierto por conformidad e incierto por el resultado de las pruebas practicas ante el Tribunal del Jurado.

${ }^{27}$ Sentencias del Tribunal Superior de Justicia de Valencia ${ }^{\circ}$ 10/2011 y 11/2011, de 16 de septiembre.

${ }^{28}$ Cfr. DE LA OLIVA SANTOS, A., La conexión en el proceso penal, op. cit., pág. 78 y ss.

${ }^{29}$ Cfr., en este sentido, DE DIEGO DÍEZ, L. A., La conformidad del acusado, op. cit., pág. 347.

30 Cfr. Sentencia del Tribunal Superior de Justicia de Valencia 2/2012, de 30 de enero. 
Por consiguiente, cuando la conformidad sólo de parte de los procesados no afecte a la continencia de la causa, no existen razones que impidan o desaconsejen el enjuiciamiento separado de los acusados en una misma causa por delitos conexos de manera que, resulta ajustado a Derecho admitir la conformidad prestada sólo por alguno de los acusados. Ahora bien, por imperativo legal ${ }^{31}$, a fin de que la conformidad sea lícita, el acusado deberá conformarse con el total de los delitos que se le imputan sin que sea, en ningún caso, posible la conformidad parcial objetiva. Recuerda, en este sentido, la doctrina del Tribunal Supremo que la regulación de la conformidad pretende, "además de asegurar la celeridad procesal a niveles mínimos para la sociedad, la búsqueda del consenso como imperativo ético-jurídico que puede venir apoyado por dos parámetros constitucionales: $1^{\circ}$ que la obtención del consentimiento del acusado a someterse a una sanción implica una manifestación de la autonomía de la voluntad o ejercicio de la libertad y desarrollo de la propia personalidad proclamada en la Constitución, art. 10.1. y $2^{\circ}$ que el reconocimiento de la propia responsabilidad y la aceptación de la sanción implican una actitud resocializadora que facilita la reinserción social, proclamada como fin de la pena, art. 25.2 CE, y que en lo posible no debe ser perturbada por la continuación del proceso y el estigma del juicio oral, finalidades que no se cumplirían mediante la conformidad parcial pretendida por el ahora recurrente» ${ }^{32}$.

\section{CONFORMIDAD EN AUSENCIA DE ALGÚN ACUSADO}

La aplicación del art. 697 LECrim, según el cual, sólo cabe la conformidad si todos los acusados se muestran conformes, resulta, cuando menos, controvertida en los supuestos en los que alguno de los acusados, contra los que se dirige la causa, no se encuentra presente. La cuestión estriba en determinar si la conformidad prestada por los acusados presentes puede alcanzar plena validez con independencia de la ausencia de otro u otros acusados.

Huelga decir que, con carácter general, la presencia del acusado en el juicio oral constituye un requisito esencial para su celebración, pues, en el proceso penal rige el principio general del derecho con-

31 Cfr. Arts. 690 y 697 LECrim.

32 Cfr. Sentencia del Tribunal Supremo ${ }^{\circ}$ 778/2006, de 12 de julio de 2006. En idéntico sentido se pronuncia la Audiencia Provincial de Guadalajara (Secc. $1^{\mathrm{a}}$ ) en su Sentencia n ${ }^{\circ}$ 18/2007, de 13 de abril de 2007 y, la Audiencia Provincial de Madrid (Secc. 29a), en su Sentencia n ${ }^{\circ}$ 258/2010, de 28 de abril de 2010. 
forme al cual nadie puede ser condenado sin haber sido previamente oído. En consecuencia, tal y como señala MONTERO ${ }^{33}$, el ejercicio del ius puniendi, en principio, no puede ejercitarse en ausencia del acusado de tal manera que, si bien el acusado no está obligado a declarar (art. 24.2 CE), sí tiene la carga de comparecer en el proceso penal ${ }^{34}$.

Esta necesaria presencia en el juicio, sin embargo, no siempre ocurre y, a tal efecto, la LECrim disciplina los casos en que, no obstante la obligación de comparecencia, el imputado no acude al llamamiento judicial, diferenciando los supuestos de rebeldía y de contumacia, pues, tal y como apunta GIMENO ${ }^{35}$, la situación del procesado con respecto a su llamada al proceso es distinta, según tenga conocimiento o no de la existencia del proceso y de algún acto de imputación judicial.

Como es sabido, la regulación originaria de la LECrim no distinguía la rebeldía y la contumacia, motivo por el cual, se sometía a ambos ausentes a un idéntico tratamiento procesal: la suspensión del proceso $^{36}$. Ello no obstante, el legislador introdujo una matización en cuanto a la referida suspensión al disponer en el art. 842 LECrim, que cuando fuesen varios los procesados y no todos hubiesen sido declarados en rebeldía, "se suspenderá el curso de la causa respecto a los re-

33 Cfr. MONTERO AROCA, J., con GÓMEZ COLOMER, J. L., MONTÓN REDONDO, A. y, BARONA VILAR, S., Derecho Jurisdiccional III op. cit., 14ª edición, pág. 87.

${ }^{34}$ AGUILERA DE PAZ ya señalaba que la indispensable asistencia del procesado al acto del juicio oral «constituye uno de los principios fundamentales del régimen en el que la misma se inspira, y hasta tal punto considera indispensable este requisito, que sólo en un caso prescinde de él por razones especialísimas derivadas de la propia naturaleza del delito perseguido, o sea cuando se siga la causa por injuria o calumnia contra particulares...». Cfr. AGUILERA DE PAZ, Enrique, Comentarios a la Ley de Enjuiciamiento Criminal, Tomo V, op. cit., pág. 306.

${ }_{35}$ Cfr. GIMENO SENDRA, V., Derecho procesal penal, $2^{\text {a }}$ edición, op. cit., pág. 234

${ }_{36}$ Cuando no existe constancia de que el imputado conoce la existencia del proceso sustanciado en su contra, nos encontramos ante un supuesto de rebeldía que se traduce en la obligación del órgano judicial de indagar su paradero y citarlo personalmente (art. 172). Si el imputado continuara en paradero desconocido, el órgano judicial mandará expedir requisitoria de búsqueda y captura (arts. 835 y siguientes LECrim) a través de la cual se fijará un plazo para que la Policía Judicial conduzca al ausente ante la presencia del Juez de Instrucción. Transcurrido dicho plazo, el imputado será declarado en rebeldía (arts. 834 y 839 LECrim) que, como efecto principal, ocasionará la suspensión del proceso penal hasta que no sea hallado. Cfr. GIMENO SENDRA, V., Derecho procesal penal, $2^{a}$ edición, op. cit., pág. 234; MUERZA ESPARZA, J., con DE LA OLIVA SANTOS, A., ARAGONESES MARTÍNEZ, S., HINOJOSA SEGOVIA, R. y, TOMÉ GARCÍA, J. A., Derecho procesal penal, $7^{a}$ edición, op. cit. págs. 162-163. 
beldes hasta que sean hallados, y se continuará respecto a los demás». De esta manera, tal y como declaraba el Tribunal Supremo en su Sentencia de 11 de febrero de 2000, "la rebeldía de uno obsta el enjuiciamiento de éste pero no es nunca condición para el enjuiciamiento de los demás» ${ }^{37}$.

Así, pues, salvedad hecha de lo prevenido en el art. 842 LECrim, la incomparecencia de cualquiera de los imputados, con independencia de su motivación, constituía, para el legislador de 1882, un motivo de suspensión del proceso. Sin embargo, el rigor de esta regla general fue atenuado con la creación del procedimiento abreviado que, tal y como apunta GIMENO $^{38}$, llevó a la práctica forense la distinción entre el rebelde y el ausente o contumaz.

Mientras que en los supuestos de rebeldía el órgano judicial despliega un mecanismo para localizar y poner en conocimiento del imputado que se está siguiendo un proceso contra él y que, en consecuencia, se requiere su presencia, la contumacia implica, de un lado, la certidumbre de que el imputado es consciente de la existencia de un proceso seguido en su contra y, de otro, la voluntad del procesado de alejarse del proceso. Así lo refleja el art. 775 LECrim al disponer que, en la primera comparecencia del imputado ante el Juez, el Secretario "le requerirá para que designe un domicilio en España en el que se harán las notificaciones, o una persona que las reciba en su nombre, con la advertencia de que la citación realizada en dicho domicilio o a la persona designada permitirá la celebración del juicio en su ausencia en los supuestos previstos en el artículo 786».

Ahora bien, el tenor literal del referido art. 775 adolece de cierta imprecisión al disponer que se celebrará el juicio en su ausencia «en los supuestos previstos en el art. 786» cuando, en puridad, la expresión literal del art. 786, prevé, dos supuestos absolutamente diferenciados:

El primer párrafo del citado artículo contiene el primer supuesto en el que establece que "si hubiere varios acusados y alguno de ellos deja de comparecer sin motivo legítimo, apreciado por el Juez o Tribunal, podrá éste acordar, oídas las partes, la continuación del juicio para los restantes». Como se desprende del texto de la norma, si bien contempla la posibilidad, de que, ante una pluralidad de acusados, se celebre el Juicio para los presentes, no prevé la posibilidad de que el no comparecido pueda ser juzgado en ausencia.

37 Cfr. Sentencia del Tribunal Supremo n 163/2000, de 11 febrero de 2000.

38 Cfr. GIMENO SENDRA, V., Derecho procesal penal, $2^{\text {a }}$ edición, op. cit., pág. 235. 
Es, en este segundo párrafo, donde explícitamente se prevé la celebración del juicio en ausencia para los casos en que sea un único acusado quien compone la parte pasiva y, a tal efecto, señala que «la ausencia injustificada del acusado que hubiera sido citado personalmente, o en el domicilio o en la persona a que se refiere el artículo 775, no será causa de suspensión del juicio oral si el Juez o Tribunal, a solicitud del Ministerio Fiscal o de la parte acusadora, y oída la defensa, estima que existen elementos suficientes para el enjuiciamiento, cuando la pena solicitada no exceda de dos años de privación de libertad o, si fuera de distinta naturaleza, cuando su duración no exceda de seis años».

En consecuencia, tal y como advierte la doctrina ${ }^{39}$, no deben confundirse los supuestos de juicio en ausencia previsto por la Ley, única y exclusivamente, para las causas en las que la parte pasiva del proceso la ostenta una única persona, de aquellos otros en los que concurren una pluralidad de acusados, en cuyo caso, el incomparecido no será objeto de un Juicio en ausencia sino, antes al contrario, de un enjuiciamiento separado ${ }^{40}$.

De todo lo dicho se desprende, que la LECrim contiene una regulación favorable a la posibilidad de juzgar a los acusados presentes, dejando pendiente de enjuiciamiento a los ausentes. Ahora bien, tal y como apunta CONDE-PUMPIDO ${ }^{41}$, la referida facultad no está exenta de ciertos riesgos e inconvenientes por lo que, el art. $762.6^{\circ} \mathrm{LE}$ Crim establece un límite: que el Tribunal estime que existen elementos suficientes para juzgarles con independencia. Así se deduce también del art. $850.5^{\circ}$ LECrim, que considera motivo de casación que «el Tribunal haya decidido no suspender el juicio para los procesados comparecidos, en el caso de no haber concurrido algún acusado, siempre que hubiere causa fundada que se oponga a juzgarles con independencia y no haya recaido declaración de rebeldia».

Una vez comprobado que la Ley permite la celebración del juicio para los acusados presentes, no obstante la incomparecencia de al-

${ }^{39}$ Cfr. CONDE-PUMPIDO TOURÓN, C., con GIMENO SENDRA, V. y, GARBERÍ LlobREgAT, J., Los Procesos Penales (Comentarios a la Ley de Enjuiciamiento Criminal con formularios y jurisprudencia), Ed. Bosch, Barcelona 2000, Tomo 6, pág. 336 y, DÍAZ PITA, M. P., Conformidad, reconocimiento de hechos y pluralidad de imputados en el procedimiento abreviado, op. cit., págs. 41 y ss.

${ }_{40}$ Cfr. GIMENO SENDRA, V., Derecho procesal penal, 2a edición, op. cit., pág. 235 y 236.

${ }^{41}$ Cfr. CONDE-PUMPIDO TOURÓN, C., con GIMENO SENDRA, V. y, GARBERÍ LLOBREgAT, J., Los Procesos Penales (Comentarios a la Ley de Enjuiciamiento Criminal con formularios y jurisprudencia), Tomo 6, op. cit., pág. 337. 
guno de los acusados, no parece que exista impedimento alguno en atribuirle eficacia a la conformidad prestada por los acusados comparecidos.

Tal afirmación, sin embargo, ha de ser matizada, toda vez que, tal y como apuntaba la Fiscalía General del Estado en su Consulta $1 / 2000$, resulta necesario, antes de determinar si es lícita o no la conformidad prestada por los acusados presentes, distinguir diferentes situaciones:

a) En aquellos supuestos en los que consta que los ausentes han sido citados correctamente y dejan de comparecer sin motivo legítimo (art. 786 LECrim) así como, en aquellos otros en los que el acusado haya sido declarado en rebeldía, no habrá inconveniente alguno en aceptar la conformidad de los acusados comparecidos pues, como ya se adelantó, la LECrim posibilita el enjuiciamiento separado de los comparecidos y de los no comparecidos (arts. 842 y 786 LECrim). Evidentemente, dicha conformidad no vinculará al acusado ausente con respecto al cual, habrá de celebrarse un ulterior Juicio.

b) Asimismo, pudiera suceder que el acusado hubiera sido citado personalmente pero, a su vez, existiera una causa que justificara su incomparecencia. En tales supuestos, si bien la Fiscalía General del Estado consideró que era motivo suficiente para impedir la conformidad de los restantes acusados, la LECrim parece ofrecer la respuesta contraria. A tal efecto, el art. $746.6^{\circ} \mathrm{LECrim}$ admite la posibilidad de celebrar el Juicio para los demás acusados en caso de incomparecencia justificada al señalar que «no se suspenderá el Juicio por la enfermedad o incomparecencia de alguno de los procesados citados personalmente...». Por consiguiente, comprobado que el ausente fue citado personalmente, la conformidad de los presentes podrá ser admitida, y ello con independencia de que la incomparecencia sea por causa justificada o injustificada.

En definitiva, se trata de garantizar que la eventual conformidad de los acusados presentes no se obtenga a espaldas del derecho que tiene toda persona a estar presente en el Juicio y, a tal fin, la eficacia de la referida conformidad se hará depender de la constatación de que ha precedido una citación personal previa del ausente que no comparece sin motivo legitimo y, en el caso del rebelde, que, previo a la declaración de rebeldía, se articularon todos los mecanismos para indagar su paradero y citarlo personalmente ${ }^{42}$.

42 Cfr. en este sentido, MIRA ROS, M. C., Régimen actual de la conformidad, op. cit., págs. 377 y 378 . 


\section{ESPECIAL REFERENCIA A LA PLURALIDAD DE ACUSADOS EN LA «CONFORMIDAD PREMIADA»}

$\mathrm{Al}$ igual que acontece en el resto de procedimientos penales, puede suceder que los delitos y faltas sustanciados a través del procedimiento de los juicios rápidos, hayan sido cometidos por una pluralidad de acusados. Ante esta tesitura, cabe preguntarse si la prohibición genérica de la conformidad parcial prevista para el sumario ordinario es aplicable para el procedimiento previsto para la conformidad de los llamados juicios rápidos.

Por una respuesta afirmativa abonaría la supletoriedad de las normas del sumario ordinario, por cuanto, como ya se adelantó, la falta de respuesta normativa para estos supuestos obliga a trasvasar las previsiones legales del sumario ordinario al resto de procedimientos. Pero, en el caso de la conformidad premiada, no aparece tan clara dicha afirmación, máxime si se repara en que, de acuerdo con lo dispuesto en el art. 795.4 LECrim, en el procedimiento para el enjuiciamiento rápido de determinados delitos, "se aplicarán las normas del Título II de este mismo Libro, relativas al procedimiento abreviado». Del mismo modo, el contenido del art. 801 LECrim comienza con una remisión expresa a la normativa reguladora de la conformidad en el procedimiento abreviado al señalar "Sin perjuicio de la aplicación en este procedimiento del art. 787...».

Las dudas o problemas interpretativos que pudiera albergar la delimitación del régimen legal supletorio para los juicios rápidos, fueron despejadas por la Fiscalía General del Estado, en su Circular 1/2003, de 10 de abril, sobre procedimiento para el enjuiciamiento rápido e inmediato de determinados delitos y faltas y de modificación del procedimiento abreviado, al señalar que, "a las diligencias urgentes les será de aplicación supletoria, en todo lo no previsto, las normas del procedimiento abreviado (art. 795.4), que se erige de ese modo en derecho supletorio de primer grado, $y$, en su defecto, las normas comunes de la LECrim (art. 758) que pasan así a ser derecho supletorio de segundo grado».

Por tal razón, la doctrina ${ }^{43}$ ha entendido que, en caso de concurrir una pluralidad de acusados, el Juez de Guardia, antes de acudir, en

${ }^{43}$ Cfr., en este sentido, CHACÓN CADENAS, M. J. y CID MOLINE, J., "Conformidad del acusado y penas alternativas a la prisión en los juicios rápidos» en, Diario La Ley n ${ }^{\circ} 5819$, op. cit., pág. 1838. y LÓPEZ JIMÉNEZ, Raquel, «La conformidad ante el Juzgado de Instrucción de Guardia» en, Revista Penal, nº 15, 2005, págs. 67-84, pág. 75 . 
vía supletoria, a lo dispuesto para el proceso penal ordinario (arts. 655 y 697 LECrim), que, como es sabido, ordenan la continuación del juicio para todos, ha de tener en cuenta lo previsto para el procedimiento abreviado en el art. $762.6^{\mathrm{a}}$ LECrim que posibilita la formación de piezas separadas.

Ahora bien, de lo dicho no debe extraerse la precipitada conclusión según la cual, por aplicación supletoria del art. 762.6ª LECrim, el Juez de Guardia se halla, automáticamente, autorizado para dictar sentencias de conformidad parcial subjetiva, pues, huelga decir que, el principio de seguridad jurídica exige que la continencia de la causa sólo se divida cuando sea procesalmente posible, circunstancia que obliga a analizar, en idéntico sentido a lo que acontece con las conformidades ordinarias, su viabilidad en los distintos supuestos:

a) Si fueran diversos delitos los cometidos por una pluralidad de acusados, el Juez de Guardia deberá realizar el correspondiente enjuiciamiento acerca del grado de conexión existente entre los hechos imputados a los diversos acusados. Si se tratara de delitos conexos imputables diferenciadamente a cada acusado, no hay obstáculos insalvables para aplicar la regla $6^{\mathrm{a}}$ del art. 762 LECrim y admitir el enjuiciamiento independiente de cada acusado, siempre y cuando la averiguación de los hechos no resulte obstaculizada por la formación de piezas separadas ${ }^{44}$. Así, pues, si fuera posible, el Juez de Guardia ordenará la apertura de la correspondiente pieza separada, posibilitará la conformidad premiada para aquellos que la interesaron para, seguidamente, remitir la sentencia de conformidad al Juez de lo Penal para su ejecución.

b) En caso de concurrir varios imputados bajo un mismo título de imputación por la comisión de un hecho con apariencia delictiva, no será de aplicación la solución prevista en la regla $6^{\mathrm{a}}$ del art. 762 LECrim, pues, no se cumple el requisito exigido por la norma, esto es, la existencia de delitos conexos. Por ello, en estos supuestos el Juez de Guardia deberá atender a la prohibición genérica contenida en las normas comunes (arts. 655 y 697 LECrim) y, en consecuencia, habrá de decretar la continuación del procedimiento para todos.

Por consiguiente, no obstante la singularidad de la conformidad premiada de los juicios rápidos respecto del resto de conformidades

${ }^{44}$ Cfr. DOIG DÍAZ, Yolanda, «La conformidad «premiada» en los Juicios Rápidos» en, La Ley, Tomo 5, 2004, D-266, pág., 1695; Molina GIMENO, F. J., «La imposibilidad de conformidad parcial ante la concurrencia de acusados y pluralidad de delitos objeto de acusación» en, Diario La Ley, op. cit., pág. 9. 
ordinarias previstas en la Ley, se deberán aplicar idénticos criterios a los establecidos para las demás modalidades de conformidad. Así, sólo será preceptiva la conformidad premiada parcial cuando se enjuicien delitos conexos y sea factible su desacumulación, por existir elementos para enjuiciarlos con independencia. Admitir la conformidad parcial en otros casos, dividiría la continencia de la causa y sería susceptible de atentar contra el derecho a la presunción de inocencia de los disconformes que, con total probabilidad, se verían perjudicados por las declaraciones de los acusados conformes.

\section{CONCLUSIONES}

A tenor del estudio realizado, podemos afirmar que la cuestión planteada no ofrece una respuesta unívoca, toda vez que, habrá que atender a las circunstancias concurrentes en cada caso concreto:

1. Cuando fuesen varios los acusados en una misma causa, por expreso imperativo legal (arts. 655 y 697 LECrim), será necesario que todos ellos presten conformidad para que se eficaz. En cualquier otro caso, el Tribunal debiera ordenar la prosecución del juicio para todos los acusados que serán juzgados tras la práctica de la prueba en el juicio oral.

Ello es así, por cuanto, admitir la conformidad parcial en tales casos, además de contradecir el tenor de la Ley, rompe la continencia de la causa y sería una solución susceptible de generar una autentica indefensión al acusado disconforme que soportaría la celebración de un juicio presidido por un órgano de enjuiciamiento, inevitablemente, influido por las declaraciones de los acusados conformes.

2. Cuestión distinta será que, en un proceso se enjuicien distintos hechos delictivos acumulados por razones de conexidad, que se imputan de manera independiente a distintos acusados. En tal supuesto, no existe inconveniente en admitir la conformidad parcial, pues, en virtud de lo establecido en el art. $762.6^{\mathrm{a}}$ LECrim, siempre y cuando existan elementos para hacerlo con independencia, el Juez podrá abrir una pieza separada en aras a dictar sentencia de conformidad para el acusado o acusados conformes, sin perjuicio de la continuación del proceso por los cauces normales para los acusados que mantengan su oposición a la acusación.

3. En los supuestos de conformidad en ausencia de algún acusado, podrá tener lugar la conformidad de los acusados presentes, toda vez que la Ley contempla la posibilidad de celebrar el juicio 
para los presentes (art. 842 y 786 LECrim), siempre y cuando, exista constancia de que el ausente, bien ha sido citado correctamente y deja de comparecer (art. 786 LECrim), bien ha sido declarado en rebeldía (art. 842 LECrim).

En definitiva, la eficacia de la referida conformidad se hará depender de la constatación de que ha precedido una citación previa del ausente que no comparece sin motivo legítimo y, en el caso del rebelde, que, previo a la declaración de rebeldía, se articularon todos los mecanismos para indagar su paradero y citarlo personalmente.

4. En los supuestos de pluralidad de acusados en la conformidad premiada, antes de acudir, en vía supletoria, a lo dispuesto para el proceso ordinario (arts. 655 y 697 LECrim), el Juez habrá de tener en cuenta lo dispuesto en las normas del procedimiento abreviado (art. 762. 6 ${ }^{\mathrm{a}}$ LECrim).

Ello no implica, sin embargo, que el Juez de Guardia quede automáticamente autorizado a dictar sentencias de conformidad parcial, pues, en todo caso, habrá de comprobar la viabilidad de la formación de piezas separadas. En consecuencia, en idéntico sentido a lo que acontece con las conformidades ordinarias, si concurren varios acusados bajo un mismo título de imputación, no será de aplicación la solución prevista en la regla $6^{\text {a }}$ del art. 762 LECrim. 
